\section{On the filtered-components approach to illusory visual contours}

\author{
THEODORE E. PARKS \\ and LARRY PENDERGRASS \\ University of California, Davis, California
}

Typically, an experiential contour is said to be an illusory contour when an abrupt step in lightness is experienced across a field of stimulation that is physically homogeneous. On the other hand, Ginsburg (1975) argued that such contours are not completely illusory in that they are physically present in the longwavelength components of a Fourier transform of the inducing stimulus. While Ginsburg's exact procedure fell into question (Tyler, 1977), Becker and Knopp (1978) have used less controversial techniques to physically reveal the illusory contours constituting the Kanizsa triangle (Kanizsa, 1955; see our Figure 1). That is, Becker and Knopp showed that physical contours corresponding to the illusory contours seen in Figure 1 are revealed when the Fourier transform of that stimulus is subjected, one axis at a time, to lowpass filtration (using coherent light) or when its unfocused projection is subjected to long-slit filtration (using incoherent light). For present purposes, these two techniques are close approximations to each other (Becker \& Knopp, p. 523), and, although both may be said to explore the contributions of long wavelengths, those perpendicular high-frequency components that are essential for the revelation of sharp illusory contours are also retained.

If Becker and Knopp's (1978) conclusions could be shown to be true for all situations in which illusory contours arise, then much current theorizing concerning these phenomena would be unneeded or, at best, merely supplementary (e.g., Spillmann, 1975; Frisby \& Clatworthy, 1975; Kennedy \& Lee, 1976; Jory \& Day, 1979; Roch \& Anson, 1979). However, Becker and Knopp subjected only that single instance of an aperiodic illusory contour to such processing. The generality of their finding is challenged by the results we obtained with an inducing stimulus (Figure 2) that is in many ways similar to Kanizsa's.

\section{BEHAVIORAL OBSERVATIONS}

Since it was first necessary to show that Figure 2 is capable of inducing an illusory figure, a group of 16

This research was supported by Grant D262 (80-81) from the University of California, Davis. T. E. Parks is affiliated with the Department of Psychology and L. Pendergrass with the Department of Physics, both at the University of California, Davis 95616.

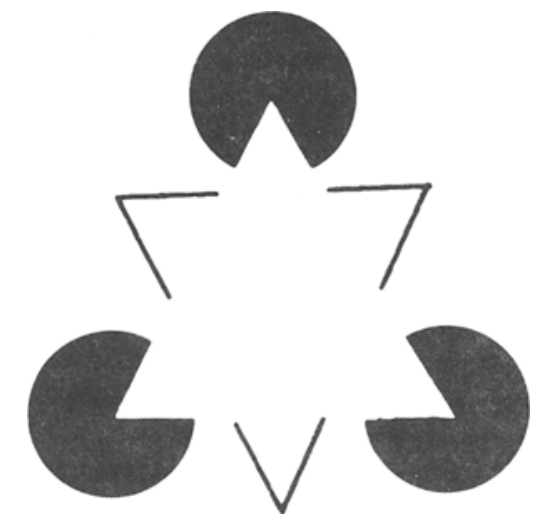

Figure 1. The stimulas pattern Introduced by Kanizsa (1955) and analyzed by Becker and Knopp (1978).

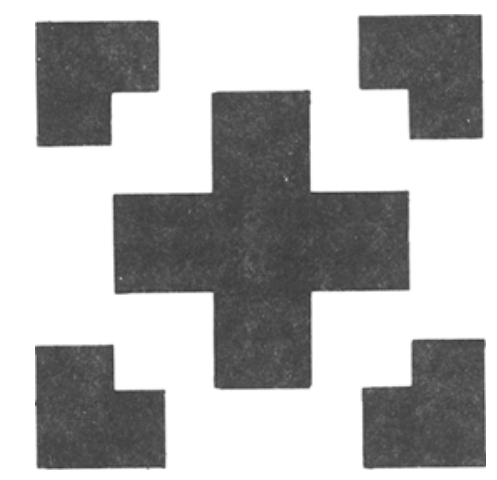

Figure 2. The present stimulus. The essential feature of this pattern for the present parpose is that if an Imaginary line is extended along and beyond any side of the lllusory square, the total extent of black lying just on one side of that line (that is, the total avallable to contribute to the long components there) is equal to the total extent lying on the opposite side.

experimentally naive university students were individually tested. First, they were given general instructions that emphasized the importance of their reporting, as accurately as they could, their visual experiences; then they were shown a typical example of an illusory figure. Viewing distance for Figure 2 was $2 \mathrm{~m}$, and the stimulus pattern was $4.5 \mathrm{~cm}$ in width and height. The experiment was conducted under ordinary room illumination. Each subject was asked the open-ended question, "What do you see here?" If any subject spontaneously used the phrase "white square," he was then asked if he specifically meant that the square area appeared to be whiter than the surround.

Of these 16 observers, 14 spontaneously included a report of a "square" (with a black cross on it) in their responses to the opening question. Of these, 8 used the more precise phrase "white square" and 
went on to indicate that that square appeared to be whiter than the surround. Thus, it is clear that Figure 2 is capable of inducing an illusory figure in many observers. The major question, of course, is whether Becker and Knopp's (1978) filtering techniques would reveal those contours.

\section{PHYSICAL OBSERVATIONS}

A slide transparency of Figure 2 was processed spatially in the two sets of apparatus diagramed in Figures $3 a$ and $3 b$, the pattern being approximately $1.2 \mathrm{~cm}$ square and enclosed within a square aperture. Either apparatus is fairly easy to assemble, requiring only readily available optical components, but the latter requires very careful alignment on an optical bench and yields its best results if parabolic lenses are available. As Becker and Knopp point out, filtering in the spatial domain (Figure 3a) with a narrow slit amounts to focusing, with a pinhole lens, the image with respect to one axis. For a description of the rather more complex steps involved in the system for frequency-domain filtering (Figure 3b), see Becker and Knopp (1978, p. 522, and Note 1). The essential point for the present purposes is that this apparatus, used in conjunction with a very narrow slit filter,

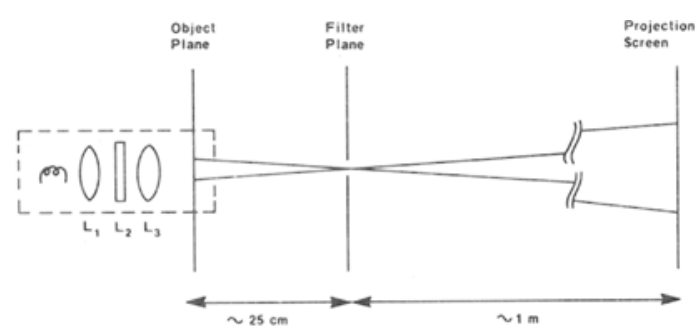

Not To Scale

a

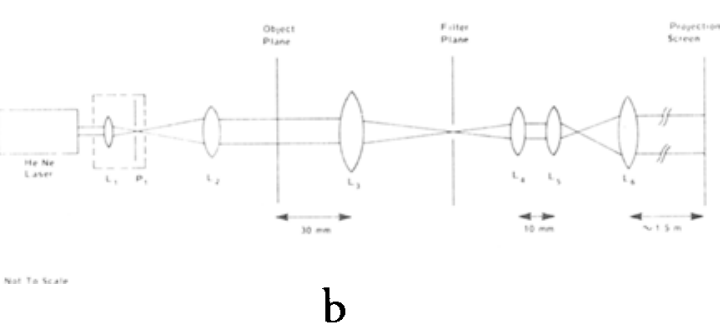

Figure 3. (a) A system for flitering in the spatial domain with incoherent light. $L_{1}, L_{2}, L_{3}$, and the object holder are all part of a standard Ektographic slide projector from which the projection lens has been removed. (b) A system for filtering in the frequency domain. Elements $L_{1}$ and $P_{1}$ are part of a commercial pinhole filter (Oriel 1522). The focal length and diameter (in centimeters) of each of the other lenses, respectively, were as follows: $25 \times 5$, $30 \times 9,15 \times 6.3,5 \times 6.3$, and $15 \times 9$. This latter system is suitable only for relatively small stimuli $(1.2 \mathrm{~cm}$ or less), whereas the former system can handle nearly full-frame 35 -mm-slide patterns.

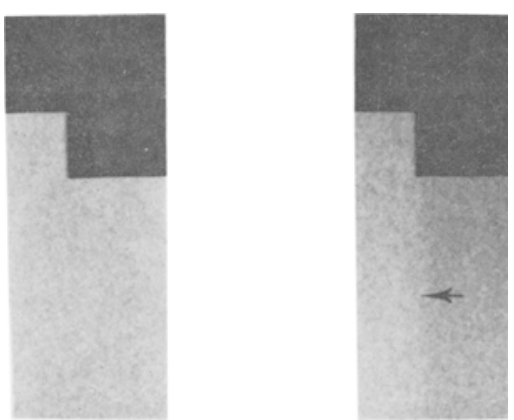

Figure 4. (Left) The result of filtering one edge of the stimulus shown in Figure 2 in the spatial domain. Similar results were obtained in the frequency domain with an adjustable narrow slit. The black corner element was added to the photograph to show the locale of one corner of the illusory square. (Right) The result obtained when the same processing was applied to a more traditional pattern (Figure 2, but without the center cross). In this case a contour is "revealed" (arrow).

low-pass filtered the Fourier transform of Figure 2 before reconstituting the remaining components on a small screen for observation. This filtering was accomplished with a minutely adjustable, doublerazor-edge slit, each blade of which, through trial and error, was positioned as closely to either side of the zero frequency point (the center of the Fourier transform) as was practicable. As indicated above, using the more economical and convenient apparatus shown in Figure 3a to filter in the spatial domain closely approximates the result of such frequencydomain filtering and has the advantage that large, easily photographed, aberration-free images can be readily produced.

The left-hand portion of Figure 4 shows the results of filtering one of the critical regions of Figure 2 in the spatial domain through a $50 \times 1 \mathrm{~mm}$ slit filter. Specifically, two corner elements (and, of course, the area between them, which would include the illusory edge that lies between them and a portion of the cross) were enclosed in a tight rectangular aperture, which was centered in the transparency holder of the slide projector during filtration and photography of the results. This procedure (filtering one of the four illusory sides at a time) ensures a balance of screen reflectance from both sides of the locale of the illusory contour with respect to the camera, a condition which is impossible to achieve for all four edges simultaneously. Furthermore, this procedure is completely legitimate, since the only information in the pattern that can possibly contribute to long-wavelength components on both sides of any contour must itself lie on both sides of that contour and its extension through the full length of the pattern (in the present case, through the corner-inducing elements). Since all four sides of the present pattern are identical, the results of filtration are also identical for all four sides of the square. As can be seen, filtering 
Figure 2 in the spatial domain failed to reveal a brightness gradient corresponding to the illusory contour. Filtering in the frequency domain produced the same (negative) results. It should be added that, although these results were obtained exclusively by optical techniques, there is no reason to believe that an attempt to reveal the illusory contours seen in Figure 2 by any reasonable digital computer algorithm would not be equally unsuccessful.

\section{DISCUSSION}

The possibility remains that some physiological analogue to filtering in the spatial or frequency domains might form an essential component of our understanding of such illusory brightness effects as the pincushion and checkerboard illusions (see Becker \& Knopp, 1978) and may even play role in some instances of illusory contours of the type introduced by Schumann (1904) and popularized by Ehrenstein (1941) and Kanizsa (1955) when the relevant components are present (see, for example, the right-hand part of Figure 4). On the other hand, the important lesson of the present observations is that such a mechanism is clearly not necessary to the latter type of illusory figure (as exemplified by the present Figure 2). In this way, the present results indirectly support the possibility that other processes play a key role in establishing such illusory contours.

\section{REFERENCES}

Becker, M. F., \& Knopp, J. Processing of visual illusions in the frequency and spatial domains. Perception \& Psychophysics, 1978, 23, 521-526.

EHRENSTEIN, W. Über abwandlungen der L. Hermannschen helligkeitserscheinung. Zeitschrift für Psychologie, 1941, 150, 83-91.

Frisby, J. P., \& Clatwonthy, J. L. Illusory contours: Curious cases of simultaneous brightness contrast? Perception, 1975, 4, 349.357.

Ginsburg, A. P. Is the illusory triangle physical or imaginary? Nature, 1975, 257, 219-220.

JoRY, M. K., \& DAY, R. H. The relationship between brightness contrast and illusory contours. Perception, 1979, 8, 3-9.

KANIzsA, G. Margini quasi-percettivi in campi con stimolazione omogenea. Rivista di Psicologia, 1955, 49, 7-30.

Kennedy, J. M., \& LeE, H. A figure-density hypothesis and illusory contour brightness. Perception, 1976, 5, 387-392.

Rock, I., \& Anson, R. Illusory contours as the solution to a problem. Perception, 1979, 8, 665-681.

Schumann, F. Einige beobachtungen über die zusammenfassung von gesichtseindrucken zu einheiten. Psychologische Studien, 1904, 1, 1-32.

Spillmann, L. Perceptual modification of the Ehrenstein illusion. In S. Ertel, L. Kemmler, \& M. Stadler (Eds.) Gestalttheorie in der modernen Psychologie (Metzger Festschrift). Darmstadt: Steinkopff, 1975.

TYLER, C. W. Is the illusory triangle physical or imaginary? Perception, 1977, 6, 603-604.

(Manuscript received August 26, 1982; accepted for publication September 8,1982 .) 